\title{
On-Farm Broiler Welfare Assessment and Associated Training
}

\section{Review}

\section{author(s)}

Butterworth $\mathrm{A}^{1}$

1 Senior Lecturer in Animal Sciences Bristol Veterinary School

University of Bristol. UK

\begin{abstract}
Around the world, people who care for animals as stock keepers, stockmen, farmers, producers are placed in a position where they can greatly influence the quality of life of the animals they manage. This is particularly true in broiler chickens, where large numbers of animals can be cared for by comparatively small numbers of people. There is an international progression to start to assess poultry welfare on farm by looking at the animals themselves using (Animal Based Measures $A B M s)$ rather than by looking exclusively at the resources provided (space, light heat, litter material - Resource Based Measures RBM's). In general, the areas being assessed are: Are the animals properly fed and supplied with water? Are the animals properly housed? Are the animals healthy? Can the animals express a range of behaviours and emotional states? Different types of organisations are starting to use ABM's Government inspection bodies - for example state veterinary staff, Research institutes - wishing to use standardized assessment methods for research, Animal Welfare NGO's, Farm assurance companies and Legislators. The WelfareQualityNetwork ${ }^{\circledR}$ (WQN) http://www. welfarequality.net/everyone has described ABM's which address twelve health and welfare criteria and has tested them on a large number of farms across Europe. Some examples from this assessment scheme are described.
\end{abstract}

\section{INTRODUCTION}

Around the world, people who care for animals as stock keepers, stockmen, farmers, producers are placed in a position where they can greatly influence the quality of life of the animals they manage. A stock keepers viewpoint on animal welfare and animal care will be enormously influenced by how animals are viewed in their society, and the ability to spent time in caring for animals can be subsumed by commercial production pressures, lack of time, lack of motivation, perceived lack of resources, perceived lack of 'value' for individual animals, lack of perception of animal issues, or sometimes through a lack of knowledge or exposure to concepts of animal care and welfare (Bracke et al., 2002, Blokhuis et al., 2003). At the moment it seems that there is interest in the possible future uptake and implementation of animal based measures in a wide range of applications. There are now moves to adopt animal based assessment in farm assurance, in local state veterinary inspection of farms, and in assisting legislators to understand the 'baseline' position regarding animal welfare on the farms in their control. Similarly, there is interest in animal based assessment for non governmental organisations who, through campaigns (including training) are influencing skill levels and capacity in producers, and by farmer groups who are working to provide management support to 
add value through improved welfare. Sometimes production companies see welfare as part of their company quality approach and so wish their staff to be trained and given capacities in animal welfare concepts or assessment methods. The experience to date has been that people from all of these types of organisations have been trained in animal welfare concepts (and sometimes in animal welfare assessment methods) and companies and others have started to use their animal welfare capacity and animal based assessment for a variety of purposes.

For these reasons, 'training' in the use of on farm animal based assessment within animal production has been used to build the 'capacities' of animal carers and keepers (Butterworth, 2009). Training in animal welfare does not take a fixed form - the type, depth and intensity of training depends very much on the needs of those to be trained. It is sometimes the case that people are not aware or have even considered that training in animal welfare issues could even be of value or interest to them. It is common for farmers, vets, legislators and enforcers of animal welfare to have a 'starting position' that, because they already work with animals on a day to day basis, and because they already have professional or work based experience, that they already have a good knowledge of animal welfare concepts (Main et al., 2001). Overall, in farm based welfare assessment methods may be seen as 'capacity building' - "activity which strengthens the knowledge, abilities, skills and behaviours of individuals and improves institutional structures and processes such that organisations can efficiently meet their goals in a sustainable way."

The key words are knowledge, abilities, skills, behaviour of individuals, improvement and 'sustainable' and the content of training material and courses may wish to address these areas to help ensure that long term capacity is built rather than to result in a short term peak in interest and motivation. This paper is based on personal exposure in the arena of training in on farm poultry welfare assessment in a number of countries, and sets out to identify some experiences and points of reference which others who carry out this type of activity may find illuminating.

\section{ON- FARM BROILER WELFARE ASSESSMENT}

There is an international progression to start to assess poultry welfare on farm by looking at the animals themselves (Animal Based Measures ABMs) rather than by looking exclusively at the resources provided (space, light heat, litter material -Resource Based Measures RBM's). Practically speaking, it is may be possible to combine RBMs and ABMs. For example, if the birds are lame (assessed using an ABM) it may be possible to predict lameness if the litter condition is poor (an RBM). Scientists have for some time suggested that ABMs could provide valid indicators of animal welfare - the sorts of questions which, in general, are being asked are:

- Are the animals properly fed and supplied with water?

- Are the animals properly housed?

- Are the animals healthy?

- Can the animals express a range of behaviours and emotional states?

To make most effective use of animal based assessment methods, it seems appropriate to make management an important part of the process.

Step 1, Measure (ABMs and RBMs) $\rightarrow$ Step 2, Analyse risk factors $\rightarrow$ Step 3, Inform (producer, purchaser) $\rightarrow$ Step 4, Support management decisions to create improvements in welfare.

In the application of the Welfare Quality protocols a set of training activities for Pigs, Poultry (Broilers and Layers) and Cattle (Dairy and Beef) has developed. The training originated from the learning and resource material which was first used to train technical and research staff in the institutes carrying out the projects within the WQ project http://www.welfarequality.net/ everyone. Since the end of the WQ project (Dec 2009) many organisations have requested training in the WQ protocols. The needs of these organisations fall into several categories:

1. Government inspection bodies - for example state veterinary staff - who wish to be trained in the protocols as a part of their commitment to general awareness of ways to assess animal welfare on farm and at slaughter. Government inspection bodies may wish to be trained in animal welfare as a part of their commitment to general awareness of ways to assess animal welfare on farm and at slaughter. In these cases training can be of value in providing information and on farm (or at slaughter) experience to strengthen capacities in the area of animal welfare. 
2. Research institutes - Wishing to use standardized assessment methods for research.

3. Animal Welfare NGO's - Who see that training in the protocols may be a basis for practical application of welfare assessment for their staff and for organisations that they work with. Animal Welfare NGO's find many ways to influence welfare change, and education programmes are a part of much of their work (RSPCA, 2010). Through this type of training, higher local animal welfare standards may increase market competitiveness, and NGOs can play a significant role in raising public and consumer awareness and through training and education programmes, and support by helping to create 'market conditions'. This can act as a driver for the development and implementation of animal welfare standards by local agencies, and in the future it is possible that these standards can be rolled out by the trained individuals and groups into farming and slaughterhouse practice.

4. Farm assurance companies - Some farm assurance companies are starting to consider the use of animal based measures in their assurance and certification work, and so are having some staff trained as an early step in trailing use of animal based measures. This has been particularly the case in certification and assurance in the organic and 'standard plus' chicken sectors (Sorensen, 2001).

5. Legislation - Use of ABM's in broiler legislation in the EU. From July 1st 2010 new welfare rules for meat chickens came into effect across the EU through Directive 2007/43/EC. In line with the requirements of the Directive, a number of animal based outcome parameters $A B M$ 's are used to identify possible on-farm welfare problems. Cumulative daily mortality rate and seven post-mortem conditions are monitored. The post-mortem conditions are: 1) Ascites/Oedema, 2) Cellulitis \& Dermatitis, 3) Dead on arrival, 4) Emaciation, 5) Joint Lesions/Arthritis, 6) Septicaemia/Respiratory and 7) Total rejections. A trigger level will also be set for Foot Pad Dermatitis (FPD). The use of $A B M$ 's as the basis for monitoring of farms for legislative and compliance purposes is a progression of the moves toward use of outcome or animal based measures in many other areas of farming, and an indicator that governments have not only recognised the use of ABMs but also committed to their use in animal welfare legislation.

The use of assurance schemes is gradually increasing in different parts of the world. 'Private' standard owners and assurance bodies can cause changes in farming standards by responding to local conditions. Private assurance schemes (not government driven), whether linked to NGOs (RSPCA Freedom Food, for example) sometime use training as part of their strategies for improving farm animal welfare. In some countries, scheme membership has moved from being voluntary, to the current position where many producers now view membership to be an essential entry requirement. In the overall assessment picture, animal welfare is part of broader ranging assessments (Rushen et al., 2010) including environmental, animal medicine use, work environment safety, food safety and retailer specific requirements and so 'animal welfare' training is often only part of a suite of trained activities.

There is an increasing emphasis of assessment of animal based measures (ABMs)- moving the inspection from 'provision' to assessment based on assessing the 'quality of animal lives' (Barnett \& Hemsworth, 1990, Butterworth et al., 2011). Once people have been trained, they can often themselves train other people (train the trainers) and so, with time, the overall level of 'capacity' increases and this can affect both animal welfare and the level of welfare understanding which the company can demonstrate to farm assurance companies and to retailers.

The training to carry out the measures in Broiler chickens takes the following form:

Day 1 - initial training in the classroom

Day 2 - practical activity on farm - consolidated by feedback and reporting of findings in the classroom after the farm visit - it is considered important to carry out a 'full' assessment on a commercial farm (preferably a real farm not an experimental or research farm) as one of the assessment days to ensure that the candidates are familiar with the time and practical details associated with actually carrying out a full assessment. Inter observer reliability testing (comparing the performance of assessors against each other, and against reference examples) takes place on the 1 day farm visit

Total time required for training $=2$ days total

Once measures have been carried out on a farm, it is possible to create a range of 'scores' and individual 
measures can be combined to give a combined or aggregated score.

As well as possible benefits of the use of animal based measures, there are clearly questions.

Who will carry the cost?

Can the measures be made in a repeatable and reliable way within the timescale of an routine assessment?

How do these measures work in relation to changing seasons?

Can a single assessment visit score provide useful information?

\section{THE WELFARE QUALITY MEASURES FOR POULTRY}

WelfareQualityNetwork ${ }^{\circledR} \quad$ (WQN) http://www. welfarequality.net/everyone created outcome or Animal Based Assessment Measures (ABM's), which address twelve health and welfare criteria and tested them on a large number of farms across Europe. The 12 criteria expand on the widely discussed 5 Freedoms (Brambell, 1965) which have been adopted as a basis for understanding and assessing farm animal welfare requirements. The twelve areas addressed by the WQN protocol are;

1. Animals should not suffer from prolonged hunger, i.e. they should have a sufficient and appropriate diet.

2. Animals should not suffer from prolonged thirst, i.e. they should have a sufficient and accessible water supply.

3. Animals should have comfort around resting.

4. Animals should have thermal comfort, i.e. they should neither be too hot nor too cold.

5. Animals should have enough space to be able to move around freely.

6. Animals should be free of physical injuries.

7. Animals should be free of disease, i.e. animal unit managers should maintain high standards of hygiene and care.

8. Animals should not suffer pain induced by inappropriate management, handling, slaughter, or surgical procedures (e.g. castration, dehorning).

9. Animals should be able to express normal, nonharmful, social behaviours (e.g. grooming).

10. Animals should be able to express other normal behaviours, i.e. it should be possible to express species-specific natural behaviours such as foraging.

11. Animals should be handled well in all situations, i.e. handlers should promote good humananimal relationships.

12. Negative emotions such as fear, distress, frustration or apathy should be avoided.

The protocol for poultry includes descriptions of each of the measures to be carried out by the assessor, and information on the sampling order, sample sizes and sample duration. The scores produced by a WQN assessment scheme can be used to provide feedback to the producer, and also to retailers and the consumer (Botreau et al, 2007). An example is given below based on the measures created to assess the common broiler condition footpad dermatitis (Shepherd \& Fairchild, 2010; Berg, 2004) (Table 1).

Table 1 - An example of a specific individual Welfare Quality measure for poultry - pododermatitis

\begin{tabular}{|c|c|}
\hline Title & Foot pad dermatitis \\
\hline Scope & $\begin{array}{l}\text { Animal-based measure: Broiler chicken at } \\
\text { slaughter }\end{array}$ \\
\hline \multirow[t]{3}{*}{ Method description } & $\begin{array}{l}\text { Foot pad dermatitis (or pododermatitis) is a } \\
\text { contact dermatitis found on the skin of the } \\
\text { foot, most commonly on the central pad, but } \\
\text { sometimes also on the toes. The skin is turned } \\
\text { dark by contact with litter and consequently } \\
\text { deep skin lesions can result. The scoring scale } \\
\text { allows an assessment of the severity of these } \\
\text { lesions (Figure 1). }\end{array}$ \\
\hline & $\begin{array}{l}\text { During three separate recording periods of } \\
\text { five minutes, score a proportion of the birds } \\
\text { passing the observation point where the foot } \\
\text { pad is visible - this will provide a sample of } n \\
\text { (line speed birds per minute (Is) x number of } \\
\text { minutes (t)). } \\
\text { Observe the birds where bottom of the feet are } \\
\text { clearly visible. } \\
\text { Record number of birds passing per minute. } \\
\text { Count number of birds with foot pad lesions } \\
\text { (b/c/d/e) - use scoring category in photographic } \\
\text { reference. } \\
\text { In the MEYN camera system, three scores are } \\
\text { reported - } 0 \text { (as } 0 \text { below), } 1 \text { (as } 1 \text { below) } 2 \\
\text { (combining all score of } 2 \text { and above }-2,2+\text { and } \\
2++ \text { ) }\end{array}$ \\
\hline & $\begin{array}{l}\text { To classify use calculation below, in which } \mathrm{t}= \\
\text { period of observation (minutes), } \mathrm{F} \text { a/b/c/d/e }= \\
\text { number of birds with foot pad lesion, } \mathrm{Is}=\text { line } \\
\text { speed (birds per minute) and } \mathrm{n}=\text { number of } \\
\text { birds observed in total }(\mathrm{t} \times \mathrm{Is} \text { ). } \\
\text { Percentage of birds with foot pad lesions in } \\
\text { each category }=(\mathrm{F}(0), \mathrm{F}(1) \text { etc.. } / \mathrm{n}) \times 100 \%\end{array}$ \\
\hline
\end{tabular}




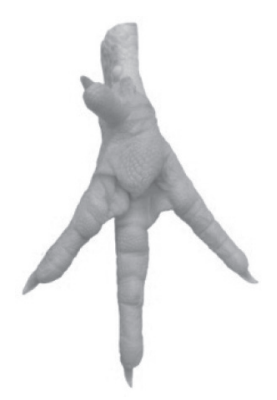

0

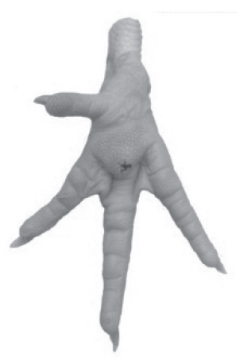

1

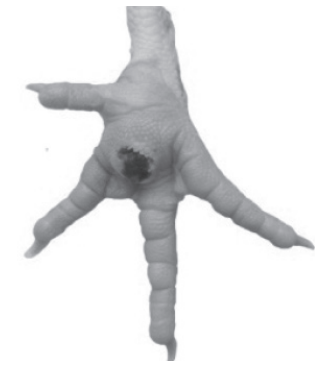

2

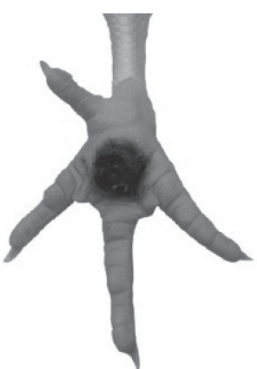

3

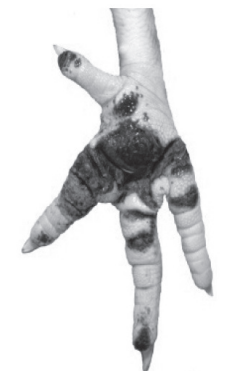

4

Figure 1 - Scale for visual observation scoring of pododermatitis.

\begin{tabular}{ll}
\hline Classification & Individual level: \\
& Percentage (\%) of birds with foot pad lesions in \\
& each category.
\end{tabular}

The percentage of birds moderately affected by foot pad dermatitis is used to calculate an index, a combined score which can be used to quantify the extent and severity of the condition on the farm. The twelve criteria areas for poultry assessment are not all addressed at the farm inspection - this is because, and particularly so for poultry, it is most efficient to collect some of the data on disease incidence, and other welfare data relevant to the catching, transport and slaughter process at the slaughterhouse or during the slaughter process. For this reason, Tables 2, 3 and 4 indicate the measures used for poultry assessment and where they are made (farm, slaughterhouse (but with data relating to the farm), or slaughterhouse (with data relating to the slaughter process).

\section{DISCUSSION}

The tools being developed in animal based measure (ABM) or outcome based measure (OBM) systems now in use by farm assurance companies, by researchers and in the legislation (2007/43/EC) Europe evolve the trend toward inclusion of assessment techniques which focus on what can be measured 'on the animal'. It seems likely that ABMs are likely to find their way into poultry farm assessment schemes in many parts of

Table 2 - Collection of data for broiler chicken on farm (actually measured on farm)

\begin{tabular}{l|c|l|l}
\hline \multirow{2}{*}{ Good feeding } & \multicolumn{2}{c}{ Welfare Criteria } & \multicolumn{1}{c}{ Measures } \\
\cline { 2 - 4 } & 2 & Absence of prolonged hunger & No measure \\
\hline \multirow{2}{*}{ Good housing } & 3 & Comfort around resting & Drinker space \\
\cline { 2 - 5 } & 4 & Thermal comfort & Plumage cleanliness, litter quality, dust sheet test \\
\cline { 2 - 5 } & 5 & Ease of movement & Panting, huddling \\
\hline \multirow{2}{*}{ Good health } & 6 & Absence of injuries & Stocking density \\
\cline { 2 - 5 } & 7 & Absence of disease & Lameness, hock burn, foot pad dermatitis \\
\cline { 2 - 5 } & 8 & $\begin{array}{l}\text { Absence of pain induced by management } \\
\text { procedures }\end{array}$ & No measure \\
\hline \multirow{2}{*}{ Appropriate behaviour } & 9 & Expression of social behaviours & No measure \\
\cline { 2 - 5 } & 10 & Expression of other behaviours & Cover on the range, free range \\
\cline { 2 - 5 } & 11 & Good human-animal relationship & Avoidance distance test (ADT) \\
\hline
\end{tabular}


Table 3 - Collection of data for broiler chicken on farm (but measured at the slaughter house) These measures are assessments of disease which are made at the slaughterhouse - but which reflect disease conditions indicating the farm life of the bird and are not reflections of the slaughter process.

\begin{tabular}{|c|c|c|c|}
\hline & & Welfare Criteria & Measures \\
\hline \multirow[t]{2}{*}{ Good feeding } & 1 & Absence of prolonged hunger & Emaciation \\
\hline & 2 & Absence of prolonged thirst & No measure \\
\hline \multirow[t]{3}{*}{ Good housing } & 3 & Comfort around resting & No measure \\
\hline & 4 & Thermal comfort & No measure \\
\hline & 5 & Ease of movement & No measure \\
\hline \multirow[t]{3}{*}{ Good health } & 6 & Absence of injuries & Breast burns, hock burn, foot pad dermatitis \\
\hline & 7 & Absence of disease & $\begin{array}{l}\text { Ascites, dehydration, septicaemia, hepatitis, pericarditis, } \\
\text { abscess }\end{array}$ \\
\hline & 8 & $\begin{array}{l}\text { Absence of pain induced by management } \\
\text { procedures }\end{array}$ & No measure \\
\hline \multirow[t]{4}{*}{ Appropriate behaviour } & 9 & Expression of social behaviours & No measure \\
\hline & 10 & Expression of other behaviours & No measure \\
\hline & 11 & Good human-animal relationship & No measure \\
\hline & 12 & Absence of fearfulness & No measure \\
\hline
\end{tabular}

the world as retailer standards start to include ABMs. There are clearly questions; Who will carry the cost, can the measures be made in a repeatable and reliable way within the timescale of an routine assessment, how would they work in relation to changing seasons, can a single farm-based score provide useful information, and can ABM's fit into existing assessment frameworks? The inclusion of ABMs is a gradual process of evolution

Table 4 - Collection of data for broiler chicken at slaughterhouse (these measures relate directly to the assessment of the slaughter process)

\begin{tabular}{|c|c|c|c|}
\hline & & Welfare Criteria & Measures \\
\hline \multirow[t]{2}{*}{ Good feeding } & 1 & Absence of prolonged hunger & Feed withdrawal time \\
\hline & 2 & Absence of prolonged thirst & Water withdrawal time \\
\hline \multirow[t]{3}{*}{ Good housing } & 3 & Comfort around resting & No measure \\
\hline & 4 & Thermal comfort & Panting on lorry and/or lairage \\
\hline & 5 & Ease of movement & Stocking density in crates \\
\hline \multirow[t]{3}{*}{ Good health } & 6 & Absence of injuries & Wing damage, bruising \\
\hline & 7 & Absence of disease & Dead on arrival (DOA) \\
\hline & 8 & $\begin{array}{l}\text { Absence of pain induced by } \\
\text { management procedures }\end{array}$ & Pre-stun shock, effectiveness of stunning \\
\hline \multirow[t]{4}{*}{ Appropriate behaviour } & 9 & Expression of social behaviours & No measure \\
\hline & 10 & Expression of other behaviours & No measure \\
\hline & 11 & Good human-animal relationship & No measure \\
\hline & 12 & Absence of fearfulness & Flapping on the line \\
\hline
\end{tabular}


(not a wave of revolution) and if ABMs do begin to make their way into farm assessment methods and the legislation worldwide, then this will most likely take place gradually and without the removal of the existing frameworks which protect farmed poultry.

\section{ACKNOWLEDGEMENT}

The work presented was part of the Welfare Quality ${ }^{\circledR}$ research project which was co-financed by the European Commission, within the 6th Framework Programme, contract No. FOOD-CT-2004-506508. The text represents the authors' views and does not necessarily represent a position of the Commission who will not be liable for the use made of such information". The text of the measure descriptions in this paper is derived from the Welfare Quality protocols for poultry. Details can be found at; http://www.welfarequality. net/everyone

\section{REFERENCES}

Barnett $J$ and Hemsworth $\mathrm{PH}$. The Validity of Physiological and Behavioural Measures of Animal Welfare. Applied Animal Behaviour Science 1990; 25: 177-187.

Berg C. Pododermatitis and hock burn in broiler chickens. In: Measuring and auditing broiler welfare. p 37-49, CABI publishing 2004

Blokhuis HJ, Jones RB, Geers R, Miele M and Veissier I. Measuring and monitoring animal welfare: transparency in the food product quality chain. Animal Welfare 2003; 12: 445-455.

Botreau R, Veissier I, Butterworth A, Bracke MBM, Keeling L. Definition of criteria for overall assessment of animal welfare. Animal Welfare 2007; 16: $225-228$.

Bracke MBM, Spruijt BM, Metz JHM, Schouten WGP. Decision support system for overall welfare assessment in pregnant sows $A$ : Model structure and weighting procedure. Journal of Animal Science 2002; 80: 1819-1834.

Brambell $\mathrm{R}$ Report of the technical committee to enquire into the welfare of animals kept under intensive livestock husbandry systems. H.M.S.O., London 1965

Butterworth A, Mench JA and Wielebnowski N'Practical Strategies to Assess (and Improve) Welfare', in Appleby MC, Mench JA, Olsson IAS, Hughes, BO (Eds.), Animal Welfare, (pp. 200-214), CABI Publishing Oxford. 2011. ISBN: 9781845936594

Butterworth A. Animal welfare indicators and their use in society. PP 371 - 389. Food Safety assurance and veterinary public health. Editors J F M Smulders and B Algers. Volume 5. Wageningen Academic Publishers, The Netherlands. 2009. ISBN 978-90-8686-122-4

Council Directive 2007/43/EC. Available at:<http://eur lex.europa. eu/LexUriServ/LexUriServ.do? uri=OJ:L:2007:182:0019:0028:EN:PDF>. Accessed on: April 2013.

Main DCJ, Webster J, Green LE. Animal Welfare Assessment in Farm Assurance Schemes. Acta Agriculturae Scandinavica 2001; Section A, Animal Science Supplementum 30, 108- 113.

Rutter, S.M. Assessing the welfare of intensive and extensive livestock. In: Proceedings of the Workshop Pasture Ecology and Animal Intake, p. 1-9. 2001

Rushen J, Butterworth A, Swanson J C. Animal Welfare Assurance: Science and application. Journal of Animal Science 2010; 89(4):1219-1228.

RSPCA (Royal Society for the Prevention of Cruelty to Animals) Supporting the implementation of the OIE animal welfare standards; The role that civil society plays.
RSPCA Publications, Wilberforce Way, Southwater, Horsham, West Sussex RH 13 9RS 2010

Shepherd EM, Fairchild BD. Footpad dermatitis in poultry. Poultry Science 2010; 89: 2043- 2051. 2010

Sørensen P. Breeding strategies in poultry for genetic adaptation to the organic environment. In: Proceedings, 4th NAHWOA Workshop, Wageningen, Netherlands. 9p. 2001 